\title{
Small spiroalkanes: ring strain effects and carbon-carbon spin-spin coupling constants
}

\author{
Natalia V. Istomina ${ }^{a}$ and Leonid B. Krivdin ${ }^{\text {a,b }}$ \\ a Technical Academy of Angarsk, Tchaikovsky St. 60, 665835 Angarsk, Russia \\ ${ }^{\mathrm{b}}$ A.E. Favorsky Irkutsk Institute of Chemistry, Siberian Branch of the \\ Russian Academy of Sciences, Favorsky St. 1, 664033 Irkutsk, Russia \\ E-mail: cps@agta.irmail.ru; krivdin_office@irioch.irk.ru
}

\begin{abstract}
Carbon-carbon spin-spin coupling constants involving and across spirocarbon are calculated in four small spiroalkanes at the high-level $a b$ initio level to reveal ring strain effects in the threemembered spiroalkane scaffold.
\end{abstract}

Keywords: Spiroalkanes, ring strain, spin-spin coupling constants, SOPPA(CCSD)

\section{Introduction}

Small spiroalkanes, spiro[2.2]pentane (1), spiro[2.3]hexane (2), spiro[2.4]heptane (3) and spiro[2.5] octane (4), provide an interesting example of spirocompounds with a unique bonding situation at spirocarbon administered by the ring strain effects ${ }^{1}$ which makes them an attractive challenge to study spin-spin coupling mechanisms in the three-membered spiroalkane scaffold. In the present communication, carbon-carbon spin-spin coupling constants involving and across spirocarbon in $\mathbf{1}$ - $\mathbf{4}$ have been calculated using the Second Order Polarization Propagator Approach in combination with the Coupled Cluster Singles and Doubles Amplitudes, SOPPA(CCSD), ${ }^{2}$ an efficient high-level $a b$ initio method to calculate second-order molecular properties based on the response functions formalism ${ }^{3}$ which is extensively used for calculation of spin-spin coupling constants in structural elucidation and stereochemical studies of organic molecules. ${ }^{4}$

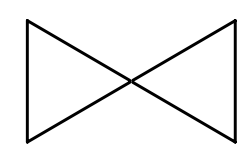

1

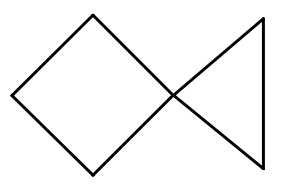

2

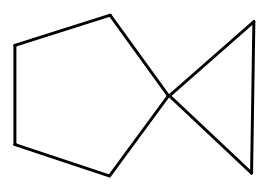

3

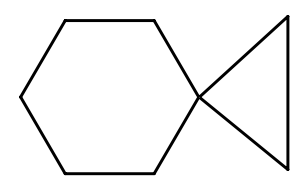

4 


\section{Results and Discussion}

The most interesting and the most unusual member of this family is spiro[2.2]pentane (1), frequently referred to in the literature as just spiropentane, the ancestor of the spiroalkanes series, a promising multipurpose starting material for many chemical and biochemical applications, which will receive our special attention further on in this study. Larger spiroalkanes have also received a good deal of interest, first of all from the synthetic point of view.

Shown in Figure 1 are the B3LYP/6-311G** optimized equilibrium structures of spiroalkanes 1 - 4 used further on in the calculation of their $J(C, C)$. Even at this stage, ring strain effects can be traced in the values of the salient equilibrium geometric parameters - bond lengths and bond angles characterizing the structural vicinity of the spirocarbon which markedly differ from those of the classical $s p^{3}$-hybridized tetrahedral carbon. As an example, ring strain effects become more and more pronounced on going from spiro[2.5]octane (4) to smaller spiroalkanes 3, 2 and 1 manifested in the spirocarbon bond angle increase from $118.9^{\circ}$ in $\mathbf{4}$ to $137.2^{\circ}$ in $\mathbf{1}$ in parallel with the attached cyclopropane bond lengths decrease from 1.506 (1.513) Á in 4 to 1.483 Á in 1 (Figure 1).

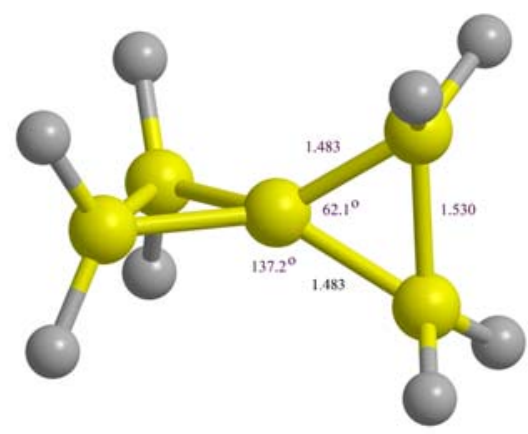

1

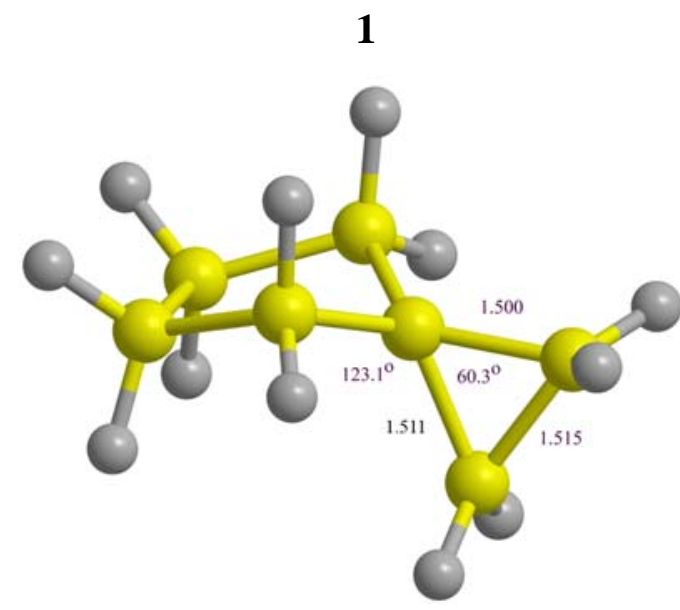

3

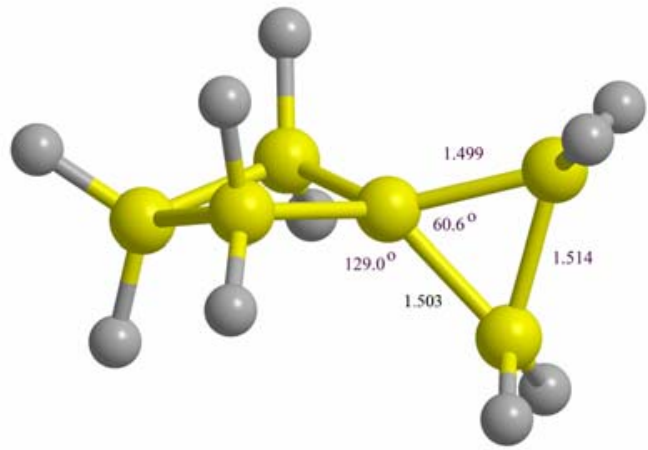

2

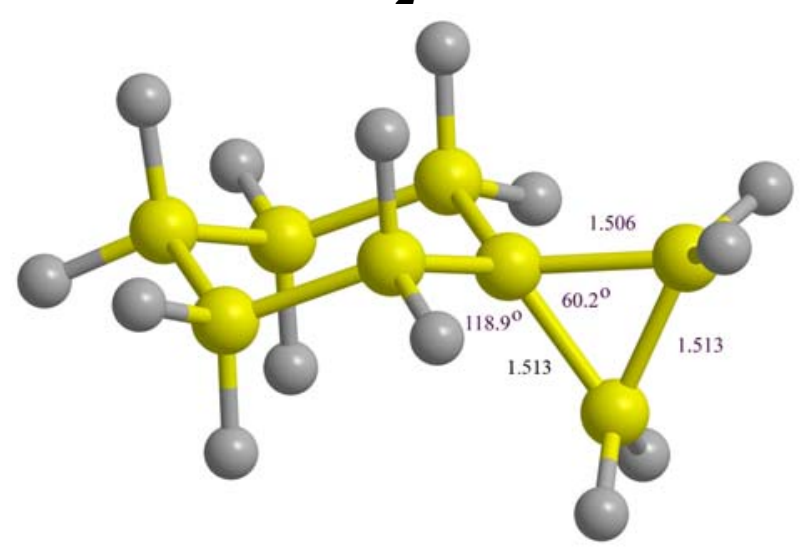

4

Figure 1. Equilibrium structures of small spiroalkanes 1 - 4 optimized at the B3LYP/6-311G** level. Bond lengths in $\AA$, bond angles in Deg. 
Along with geometric parameters, $J(\mathrm{C}, \mathrm{C})$ provides the most straightforward insight into ring strain effects in cyclic molecules. ${ }^{1}$ Thus, the most obvious trend is the marked increase of the one-bond $J(\mathrm{C}, \mathrm{C})$ with the increase of the $s$-character of the corresponding carbon-carbon bond between both coupled nuclei. ${ }^{5}$ Keeping this in mind, we have calculated $J(\mathrm{C}, \mathrm{C})$ involving and across spirocarbon in the series of $\mathbf{1}-\mathbf{4}$ at the SOPPA(CCSD) level using their B3LYP/6$311 \mathrm{G}^{* *}$ optimized equilibrium structures taking into account all four coupling contributions (Table 1).

Table 1. Spin-spin coupling constants $J(C, C)$ of spiroalkanes 1 - 4 involving and across spirocarbon calculated at the SOPPA(CCSD) level ${ }^{\mathrm{a}}$

\begin{tabular}{|c|c|c|c|c|c|c|c|}
\hline $\begin{array}{l}\text { Com- } \\
\text { pound }\end{array}$ & $\begin{array}{c}\text { Numbering of } \\
\text { atoms }\end{array}$ & $\begin{array}{c}\text { Coupling } \\
\text { constant }\end{array}$ & $J_{\mathrm{OD}}$ & $J_{\mathrm{OP}}$ & $J_{\mathrm{SD}}$ & $J_{\mathrm{FC}}$ & $J$ \\
\hline 1 & & $\begin{array}{l}J(\mathrm{C}-1, \mathrm{C}-2) \\
J(\mathrm{C}-1, \mathrm{C}-3) \\
J(\mathrm{C}-3, \mathrm{C}-4)\end{array}$ & $\begin{array}{l}0.2 \\
0.2 \\
0.2\end{array}$ & $\begin{array}{l}0.1 \\
-0.9 \\
-0.9\end{array}$ & $\begin{array}{l}-0.1 \\
-0.3 \\
-0.3\end{array}$ & $\begin{array}{l}10.0 \\
23.1 \\
23.1\end{array}$ & $\begin{array}{l}10.2 \\
22.1 \\
22.1\end{array}$ \\
\hline 2 & & $\begin{array}{l}J(\mathrm{C}-1, \mathrm{C}-2) \\
J(\mathrm{C}-1, \mathrm{C}-3) \\
J(\mathrm{C}-3, \mathrm{C}-4)\end{array}$ & $\begin{array}{l}0.2 \\
0.2 \\
0.3\end{array}$ & $\begin{array}{c}-0.3 \\
-0.9 \\
0.7\end{array}$ & $\begin{array}{c}-0.1 \\
-0.2 \\
1.0\end{array}$ & $\begin{array}{l}12.3 \\
16.4 \\
35.1\end{array}$ & $\begin{array}{l}12.1 \\
15.5 \\
37.0\end{array}$ \\
\hline 3 & 4 & $\begin{array}{l}J(\mathrm{C}-1, \mathrm{C}-2) \\
J(\mathrm{C}-1, \mathrm{C}-3) \\
J(\mathrm{C}-3, \mathrm{C}-4)\end{array}$ & $\begin{array}{l}0.2 \\
0.3 \\
0.3\end{array}$ & $\begin{array}{l}-0.2 \\
-0.9 \\
-0.5\end{array}$ & $\begin{array}{c}-0.1 \\
-0.2 \\
0.8\end{array}$ & $\begin{array}{l}12.1 \\
18.2 \\
41.7\end{array}$ & $\begin{array}{l}12.0 \\
17.4 \\
42.3\end{array}$ \\
\hline 4 & & $\begin{array}{l}J(\mathrm{C}-1, \mathrm{C}-2) \\
J(\mathrm{C}-1, \mathrm{C}-3) \\
J(\mathrm{C}-3, \mathrm{C}-4)\end{array}$ & $\begin{array}{l}0.2 \\
0.3 \\
0.3\end{array}$ & $\begin{array}{l}-0.3 \\
-0.9 \\
-0.5\end{array}$ & $\begin{array}{l}-0.1 \\
-0.2 \\
0.9\end{array}$ & $\begin{array}{l}12.9 \\
17.0 \\
41.9\end{array}$ & $\begin{array}{l}12.7 \\
16.2 \\
42.6\end{array}$ \\
\hline
\end{tabular}

${ }^{a}$ Coupling constants and their contributions are in Hz. All four coupling contributions are taken into account: orbital diamagnetic $\left(J_{\mathrm{OD}}\right)$, orbital paramagnetic $\left(J_{\mathrm{OP}}\right)$, spin dipolar $\left(J_{\mathrm{SD}}\right)$ and Fermi contact $\left(J_{\mathrm{FC}}\right)$ to make up the resulting total value of coupling constant $(J)$.

It is noteworthy that $J(\mathrm{C}, \mathrm{C})$ in cyclopropane could be interpreted as arising from the two physically quasi-independent coupling pathways, namely one-bond, ${ }^{1} J(\mathrm{C}, \mathrm{C})$, and two-bond (geminal), ${ }^{2} \mathrm{~J}(\mathrm{C}, \mathrm{C})$. It is only the one-bond contribution, ${ }^{1} \mathrm{~J}(\mathrm{C}, \mathrm{C})$, which is determined by the carbon-carbon bond s-character. On the other hand, the geminal contribution, ${ }^{2} J(\mathrm{C}, \mathrm{C})$, which is 
not transmitted through the latter, is almost independent on this factor. Thus the unusually low values of $J(C, C)$ in cyclopropane could be attributed to the two different factors, namely (i) the reduced carbon-carbon bond s-character (which is mainly due to steric strain); and (ii) the negative contribution of the geminal coupling pathway to the total $J(\mathrm{C}, \mathrm{C})$ value. Indeed, cooperation between these two factors results in a dramatic decrease of $J(\mathrm{C}, \mathrm{C})$ measured in cyclopropane $\left(12.4 \mathrm{~Hz}^{6}\right)$.

However, this situation is not as obvious as one might assume based on the simple additive dual-pathway model. In spite of its obvious vividness, this interpretation was found by $\mathrm{Wu}$ and Cremer $^{7}$ to be highly misleading; according to their theoretical results, for cyclopropane, the onebond contribution of $J(\mathrm{C}, \mathrm{C})$ is as much as $54.4 \mathrm{~Hz}$, as it should be for a carbon-carbon bond with substantial $p$-character. Accordingly, through-space $(-27.1 \mathrm{~Hz})$ and two-bond $(10.1 \mathrm{~Hz})$ contributions lead in sum to a typical geminal ${ }^{2} J(C, C)$ of a strongly strained carbon ring (-17.1 $\mathrm{Hz}$ ). The path interaction term is $-24.5 \mathrm{~Hz}$ reflecting the strong interaction between the carboncarbon bond orbitals in the three-membered ring. The resulting total $J(C, C)$ in cyclopropane is reduced by the two-bond and the paths interaction contributions to $12.9 \mathrm{~Hz}$, which is in excellent agreement with the experimental value of $12.4 \mathrm{~Hz}$. Whatever the case, dramatically low $J(\mathrm{C}, \mathrm{C})$ in cyclopropane as compared to the open-chain aliphatics and/or large alicyclics, reflects the interplay of the ring strain effects, and basically, the lower this coupling, the stronger are the ring strain effects.

As follows from the data presented in Table 1, total values of both $J(C, C)$ calculated in the three-membered spiroalkane scaffold of $\mathbf{1}-\mathbf{4}$, namely $J(\mathrm{C}-1, \mathrm{C}-2)$ between two peripheral carbons and $J(\mathrm{C}-1, \mathrm{C}-3)$ involving spirocarbon fall into ranges accordingly, 10.2-12.7 and 15.5$17.4 \mathrm{~Hz}$ (which is close to the experimental value of $12.4 \mathrm{~Hz}$ in cyclopropane itself $\mathrm{f}^{6}$ ) thus showing strong ring strain effects in all four compounds. The only exception is the increased value of $J(C-1, C-3)=22.1 \mathrm{~Hz}$ (experimental value $20.2 \mathrm{~Hz}^{8}$ ) in $\mathbf{1}$ which is due to the increased scharacters of the exocyclic carbon hybrids of the second cyclopropane ring involving spirocarbon. The values of $J(\mathrm{C}-3, \mathrm{C}-4)$ noticeably increase from $10.2 \mathrm{~Hz}$ in 1 to $42.6 \mathrm{~Hz}$ in 4 thus showing the reduction of the ring strain effects at spirocarbon with increasing ring size of the second spiroalkane moiety.

It was noticed by one of the referees that $J(\mathrm{C}-1, \mathrm{C}-3)$ demonstrates irregular behavior in the series of $2-4$ being $15.5 \mathrm{~Hz}$ in $2,17.4 \mathrm{~Hz}$ in 3 and $16.2 \mathrm{~Hz}$ in 4 . Indeed, one would have expected the steady decrease of this coupling when going from 2 to 3 and finally to 4 as a result of the ring strain weakening of the second spiroalkane moiety leading to the decrease of the cyclopropanic $\mathrm{C}-3$ hybrid s-character. The only rational explanation of this irregularity is that only one of the two unequal cyclopropanic proximal bonds was taken into account in the calculation of $J(\mathrm{C}-1, \mathrm{C}-$ 3). Originally, we did not pay much attention to this fact since the overall effect did not exceed 2 $\mathrm{Hz}$ in the series of 2-4 while it was ca. $6 \mathrm{~Hz}$ when going to $\mathbf{1}$. 


\section{Conclusions}

It follows from the calculations performed of carbon-carbon spin-spin coupling constants involving and across spirocarbon in four small spiroalkanes that considerable ring strain effects come into play at the spirocarbon in this series with the latter fading out on increasing the ring size of the second spiroalkane moiety.

\section{Experimental Section}

General Procedures. Geometry optimizations were performed with the GAMESS code ${ }^{9}$ at the B3LYP/6-311G** level assuming $D_{2 d}$ symmetry for 1 and Cs symmetry for $\mathbf{2}$ - 4. Calculations of spin-spin coupling constants have been carried out taking into account all four non-relativistic coupling contributions with the DALTON package ${ }^{10}$ at the SOPPA(CCSD) level using the B3LYP/6-311G* geometries with the correlation-consistent basis set cc-pVDZ augmented with two core s-functions of Woon and Dunning on coupled carbons, as specified elsewhere. ${ }^{11}$ The rest of the atoms (uncoupled) were specified with cc-pVDZ without polarization $p$-functions on hydrogens.

\section{Acknowledgements}

Financial support from the Russian Foundation for Basic Research (Grant 08-03-00021) is acknowledged.

\section{References and Notes}

1. Krivdin, L. B. Magn. Reson. Chem. 2005, 43, 101.

2. Enevoldsen, T.; Oddershede, J.; Sauer, S. P. A. Theor. Chem. Acc. 1998, 100, 275.

3. Helgaker, T.; Jaszuński, M.; Ruud, K. Chem. Rev. 1999, 99, 293.

4. Krivdin, L. B.; Contreras, R. H. Annu. Rpts. NMR Spectrosc. 2007, 61, 133.

5. Krivdin, L. B.; Kalabin, G. A. Prog. NMR Spectrosc. 1989, 21, 293.

6. Weigert, F. J.; Roberts, J. D. J. Am. Chem. Soc. 1972, 94, 6021.

7. Wu, A.; Cremer, D. Phys. Chem. Chem. Phys. 2003, 5, 4541.

8. Bertrand, R. D.; Grant, D. M.; Allred, E. L.; Hinshow, J. C.; Strong, A. B. J. Am. Chem. Soc. 1972, 94, 997. 
9. Schmidt, M. W.; Baldridge, K. K.; Boatz, J. A.; Elbert, S. T.; Gordon, M. S.; Jensen, J. H.; Koseki, S.; Matsunaga, N.; Nguyen, K. A.; Su, S. J.; Windus, T. L.; Dupuis, M.; Montgomery, J. A. J. Comp. Chem. 1993, 14, 1347.

10. Angeli, C.; Bak, K. L.; Bakken, V.; Christiansen, O.; Cimiraglia, R.; Coriani, S.; Dahle, P.; Dalskov, E. K.; Enevoldsen, T.; Fernandez, B.; Haettig, C.; Hald, K.; Halkier, A.; Heiberg, H.; Helgaker, T.; Hettema, H.; Jensen, H. J. A.; Jonsson, D.; Joergensen, P.; Kirpekar, S.; Klopper, W.; Kobayashi, R.; Koch, H.; Ligabue, A.; Lutnaes, O. B.; Mikkelsen, K. V.; Norman, P.; Olsen, J.; Packer, M. J.; Pedersen, T. B.; Rinkevicius, Z.; Rudberg, E.; Ruden, T. A.; Ruud, K.; Salek, P.; Sanchez de Meras, A.; Saue, T.; Sauer, S. P. A.; Schimmelpfennig, B.; Sylvester-Hvid, K. O.; Taylor, P. R.; Vahtras, O.; Wilson, D. J.; Ågren, H. Dalton. A Molecular Electronic Structure Program, Release 2.0, 2005.

11. Sauer, S. P. A.; Krivdin, L. B. Magn. Reson. Chem. 2004, 42, 671. 